\title{
fiscalidade e administração fazendária na bahia durante a guerra holandesa*
}

\author{
Wolfgang Lenk \\ Doutor em Economia Aplicada pela Universidade Estadual de Campinas e Professor do Instituto \\ de Economia da Universidade Federal de Uberlândia
}

\section{RESUMO}

As necessidades financeiras da defesa da Bahia, durante a invasão holandesa, exigiram uma reorganização da fiscalidade na capitania.Ao longo desse processo, o provedor-mor (e seu regimento, de viés fiscalista) passou por anos dificeis de isolamento político, até o extremo da perseguição.A superação da crise no ofício apenas ocorreu com a delegação de várias de suas funções ao Senado da Câmara de Salvador e com o exercício da "suavidade" no governo da Fazenda Real - i.e., o relaxamento das normas em favor da composição política com a fração mais poderosa dos senhores de engenho. $\mathrm{O}$ episódio oferece diferentes sinais da importância relegada pela Coroa para o bom relacionamento com os senhores da colônia, principalmente em seus interesses mercantis, com o explícito objetivo de manter a economia colonial do açúcar em funcionamento.

Palavras-chave: Fiscalidade, História, Bahia colonial, Brasil holandês, Estado fiscal-militar

\section{Abstract}

The funding for the portuguese defense of Bahia against the Dutch invasion demanded a broad rearrangement of the captaincy's taxation. During that process, the provedormór (the highest ranking trasury official) underwent a troubled period, resulting in political isolation, even persecution. The crisis in the office was finally solved after several of its functions were delegated to the Senado da Câmara (ou Municipal Council) of Salvador, at the same time that the portuguese rulers of the Estado do Brasil called for the exercise of "gentleness" in the administration of that treasury. The episode is na evidence of the importance given by the Crown to a good political relationship with the colony's ruling class, particularly in its mercantile interests, with the explicit goal to maintain production and exports from the colonial sugar economy.

Key-words: Tributation, History, Bahia, colonial history, Dutch Brazil, Fiscal-military State

* O presente trabalho é derivado de algumas das conclusões da Tese de Doutoramento do autor, defendida na Universidade Estadual de Campinas, em 2009. Submetido em julho, 2010; aceito em outubro, 2010. 
Nos últimos anos, a esfera política da vida no Brasil colonial tem sido objeto de intenso debate. São muitos os pesquisadores que se têm confrontado com a necessidade de compreender o exercício do poder político nas diferentes capitanias, os elementos constitutivos do Estado português na colônia (ou, como preferem alguns, a variedade de instituições políticas daquela realidade), bem como tem sido objeto de muitas pesquisas a ativa participação dos colonos nas instâncias políticas de dominação. Laura de Mello e Souza, ao retraçar a historiografia desse debate, percebeu duas linhas de interpretação: aquelas que enfatizam os aspectos centralizantes da política colonial (sobretudo na autonomia da esfera política, a subordinação da sociedade) ou os aspectos de descentralização (a inocuidade da norma ou a norma particularista, a provisoriedade, a descontinuidade, o patrimonialismo e a flexibilização do poder aos agentes locais). Entretanto, como afirmam a autora e outros estudiosos do tema, a história da esfera política na colônia não pode prescindir do seu enquadramento social, nem se pode pensar suas instituições à margem do escravismo ou do sistema mercantilista (SOUZA, 2006).

O estudo da fiscalidade colonial pode contribuir e tem de fato contribuído para esse debate, sobretudo com a publicação das contas da Fazenda Real nos séculos XVI e XVII, revistas e sistematizadas por Angelo Carrara (2010), o que certamente vai subsidiar o trabalho na história econômica da América portuguesa. A recorrência de revoltas contra o fisco em todas as capitanias, a partir da Restauração de 1640, foi objeto de estudo de Luciano Figueiredo (1996; 2005), que nelas encontrou momentos da imanente tensão, causada pelo sistema de exploração colonial.Ao mesmo tempo,Alberto Gallo (2008) vê, no caráter regressivo da fiscalidade e nos mecanismos de sua apropriação pelos setores dominantes na sociedade, a constituição de um "pacto fiscal", como meio de compensação e pacificação das elites frente ao esbulho resultante do "pacto colonial". Seguindo essa toada, pretende-se aqui compreender a administração fazendária do Governo Geral durante a invasão holandesa, como um capítulo específico desse processo, durante o qual os problemas envolvidos na fiscalidade colonial se tornaram dramáticos. Primeiro, devido ao grande volume de recursos necessários ao financiamento da defesa de Salvador, principal baluarte que garantia a presença portuguesa no território. Segundo, em função da importância 
que assumiria a segurança política da colônia, a lealdade de seus habitantes, visto que a maior fragilidade do Brasil holandês residia exatamente no conflito que se instaurou entre senhores de engenho e comerciantes do açúcar.

\section{A tributação e o Provedor-mor da Fazenda}

A disputa com os holandeses pela dominação do Nordeste açucareiro apresentou um enorme desafio para a administração da Fazenda Real, pelo sistema do Governo Geral. A defesa da capital colonial exigia a prontidão de um exército regular de aproximadamente dois mil homens em armas, cuja disciplina dependia largamente do pagamento de soldos. Para tanto, cada um dos dois terços do presídio baiano exigia anualmente (e aproximadamente) quinze contos de réis do erário régio. Em 1631, com o desembarque do "terço novo" em Salvador e mais socorros de infantaria do Reino, o governador dizia precisar de trinta e três contos para o presídio. ${ }^{1}$ Em 1642 , essa conta era estimada em trinta e oito contos - o que, a depender da estimativa do açúcar produzido e comercializado naquele ano, representava algo entre quinze e vinte por cento de toda a renda da sua produção. ${ }^{2}$ No período anterior à guerra, as pequenas guarnições militares da capitania consumiam seis contos de réis ao ano; toda a folha de pagamento - dos oficiais da Coroa e da Igreja - somava dezoito contos (o que não chega a sete por cento do valor das exportações de açúcar). ${ }^{3}$ Portanto, ressalvadas as oscilações no exército,

Livro primeiro do governo do Brasil (1607-1633). Rio de Janeiro: MRE, 1958:53-70; BIBLIOTECA DA AJUDA/ CÓDICE 49-X-10/ RELAÇÃO e recenseamento de toda a gente de guerra do terço do mestre de campo D.Vasco Mascarenhas, que de presídio assistem na cidade da Bahia; Salvador, 22 de junho de 1629 [fls. 136-140]; Documentos Históricos do Arquivo Municipal: Atas da Câmara (DHAM:AC), vol. I, p. 188.

2 ARQUIVO HISTÓRICO ULTRAMARINO (AHU)/BA/SÉRIE LUÍSA DA FONSECA/CARTA do governador Antônio Teles da Silva para Sua Majestade, acerca dos efeitos que ali há para sustento do presídio, sobre o pau brasil que Filipe Bandeira de Melo, ausente em Castela, cortou em Porto Seguro, algum do qual vendeu aos jesuítas; Bahia, 28 de janeiro de 1644 [cx. 9, doc. 1030]. A estimativa da participação da arrecadação na renda foi feita a partir do valor do contrado dos dízimos.

3 Ibidem. "Registro da folha geral deste Estado" (1616), in Documentos Históricos da Biblioteca Nacional (DHBN), v. 15, pp. 25-66; AHU/BA/SÉRIE LUÍSA DA FONSECA/ CARTA do governador Antônio Teles da Silva sobre a ordem régia que teve pelo 
alojado em Salvador, e demais despesas da guerra (que, em geral, agravaram o quadro aqui desenhado), que haviam mais que dobrado a necessidade de recursos para a Fazenda Real na Bahia.

Do lado das receitas, a fiscalidade local enfrentava uma variedade de obstáculos. Formalmente, uma gama de setores da sociedade havia sido agraciada com privilégios de isenção tributária, por meio de uma legislação dispersa e particularista que dificultava sua reconstituição. Eram concessões ao bispado, às ordens religiosas (sobretudo, aos jesuítas), aos conventos e também à Santa Casa de Misericórdia (à ordem, como um todo, e a seus provedores, em específico). Por algum tempo, os hábitos das Ordem de Cristo também conferiram isenções ao portador, por extensão dos direitos das antigas Ordens do Templo e de Calatrava. ${ }^{4}$ A Coroa não deixou de registrar o interesse: "há inconveniente na concessão do hábito dessa ordem aos moradores do Brasil, em razão de com ele se quererem isentar de pagar dízimos" (ALBUQUERQUE, 1968:58-9). Senhores de engenho eram também privilegiados com a "liberdade dos dez anos", isenção no pagamento de dízimos para proprietários de engenhos construídos na década anterior. ${ }^{5}$ Entre 1613-1615, a "Junta da Fazenda" de André Farto da Costa calculou que um terço do açúcar da Bahia e de Pernambuco deixava de pagar dízimos, pelo recurso abusivo e incomedido à "liberdade dos engenhos” (JOYCE JR., 1974:212). Com todas as isenções, não é dificil cotejar os grupos que constituíam a base da tributação. Charles Boxer já fez essa conta: "the result was that the burden of taxation was borne by the poor, who found that most of the necessities of life were taxed, and by the sugar planters of the Reconcavo" (BOXER, 1962:141-50; 1965:50).

Conselho da Fazenda para se ter dois mil homens efetivos para a defesa desta cidade; Salvador, 23 de setembro de 1642 [cx. 8, doc. 976]; BIBLIOTECA NACIONAL DE LISBOA (BNL)/MANUSCRITOS/INFORMAÇÃO sobre o Estado do Brasil; 15 de novembro de 1652 [mss. 218, n. 134].

4 Durante a guerra, as Ordens de Avis e Santiago já haviam sido destituídas do privilégio, que então era restrito à Ordem de Cristo (Albuquerque, 1968; Olival, 2001).

5 Os primeiros alvarás para os "dez anos da liberdade que concedi aos moradores e povoadores das ditas partes e pessoas que nelas fizerem engenhos de açúcares" são de 1551 (MENDONÇA, Marcos Carneiro de. Raízes da formação administrativa do Brasil. Rio de Janeiro: IHGB, 1972:251; RICUPERO, Rodrigo M. "Honras e mercês: poder e patrimônio nos primódios do Brasil”. São Paulo, USO, 2005:123. 
À margem das normas da Coroa, há que se considerar outro tipo de privilégio, político e informal; outra maneira de resistência ao crescimento da carga fiscal. Trata-se do acesso aos mecanismos de cobrança da tributação, portanto, aos meandros pelos quais ela se desencaminhava. Quanto maiores eram as alíquotas do fisco, maior era o prêmio à sonegação, de tal maneira que a boa arrecadação dos impostos estabelecidos (mesmo os indiretos) sempre foi um grande problema. Era conhecida a difusão de "más cobranças", quando se tratava da imposição dos vinhos, uma das mais importantes fontes de arrecadação, ${ }^{6}$ em particular, nas embarcações da praia. ${ }^{7}$ O Senado da Câmara, em geral, resistia à racionalização da cobrança, que, ademais, corria por sua responsabilidade. ${ }^{8}$ O Governo Geral tentou, em mais de uma ocasião (e sempre sem sucesso), arrendar a cobrança da imposição dos vinhos, ou negociar um estanco, de modo a reduzir os desvios.

Com tantas resistências, privilégios e a escassa receita para as despesas de guerra, não era fácil a vida dos oficiais da Fazenda Real, em particular a do Provedor-mor, que era responsável pela supervisão dos demais oficiais e das atividades do erário, como um todo, sobretudo porque eram todos limitados pelo viés francamente fiscalista dos regimentos, bem como pela frágil separação entre a fazenda da Coroa e sua fazenda pessoal. O cargo de Provedor-mor havia sido criado em 1548, como componente do sistema do Governo Geral, em grande parte com o intuito de fiscalizar o exercício das receitas e das despesas do erário nas capitanias do Brasil. O tesouro na Bahia também haveria de centralizar os saldos positivos dos demais almoxarifes e recebedores, nas outras

6 AHU/BA/SÉRIE LUÍSA DA FONSECA/REGIMENTO e provisões que se passaram sobre a Junta para arrecadação da Fazenda Real que se fez no Brasil, 19 de setembro de 1612 [cx. 1, doc. 35].

7 AHU/BA/SÉRIE LUÍSA DA FONSECA/PAPEL que se deu no Consulta do Conselho Ultramarino em defesa de Pedro Cadena deVilhasanti, 13 de janeiro de 1637, [cx. 8, doc. 894]; CONSULTA do Conselho Ultramarino, 07 de agosto de 1638, [cx. 8, doc. 850]; CARTA de Pedro Cadena de Vilhasanti a S.M., 03 de novembro de 1638, [cx. 7, doc. 805]; Em 1646, novamente era necessária uma devassa sobre as atividades dos guardas que supervisionavam a descarga dos vinhos (Ata da Câmara de Salvador, 27 de junho de 1646, DHAM:AC, v. 2, p. 311).

8 Ata da Câmara de Salvador, 26 de agosto de 1628 (DHAM: AC, v. 1, p. 103). 
praças do litoral. ${ }^{9}$ O regimento emulava na colônia os dispositivos legais que, no Reino, buscavam angariar recursos das diversas localidades a crédito do centro político, a corte de Lisboa. Pouco era previsto para a ocorrência de saldos negativos em tesourarias específicas; no mais das vezes, as ordenações e as leis extraordinárias da Fazenda tratavam da execução de créditos da Coroa em posse de seus oficiais. ${ }^{10}$ O quarto capítulo do Regimento dos Provedores do Brasil, de 1548, chegava a postular que "não poderão os ditos Provedores receber lanços em as ditas Rendas nos outros anos seguintes, em menos quantia de em que se arremataram o ano atrás". ${ }^{11}$ Segundo carta régia de fevereiro de 1627, não era permitido que tesoureiros ou almoxarifes deixassem contas em aberto para o sucessor. ${ }^{12}$ Pressupunha-se que as fontes de receita eram suficientes para a folha de despesas, e a maior das preocupações era com a probidade e a boa observação das normas do erário. ${ }^{13}$

9 "Regimento dos provedores da Fazenda Real nas capitanias do Brasil", 17 de dezembro de 1548, in Mendonça, Raízes da formação administrativa do Brasil, op. cit.

Durante o início do século XVII, a Coroa instituiu "Juntas de execução dos contos" para acelerar a auditoria sobre os oficiais da Fazenda e a liquidação de ativos a receber (ver Alvará de 17 de outubro de 1604 e Carta régia de 17 de novembro de 1627, in Colecção Chronológica da Legislação Portuguesa (CCLP); AHU/BA/SÉRIE LUÍSA DA FONSECA/MEMÓRIA dos efeitos que há na Fazenda Real de onde se pode tirar dinheiro; [cx. 8, doc. 889]. Entretanto, não eram poucas as resistências, nem o sistema era completamente racional e centralizado. As reformas de 1591 (criação do Conselho da Fazenda) e de 1627 (criação da Casa dos Contos) não revogaram em profundidade a autonomia dos contadores e dos administradores do erário em cada localidade, concedida nas Ordenações de 1514. Os oficiais continuaram a acumular as funções de coleta, custódia, e dispêndio, com o que muito da contabilidade que submetiam à supervisão dos vedores era efetivamente ilusória (JOYCE JR., Spanish influence, op. cit., p. 141).

11 Regimento dos Provedores da Fazenda Real nas capitanias do Brasil, 17 de dezembro de 1548, in Mendonça, op. cit., 1972.

Carta régia de 14 de fevereiro de 1627, in DHBN, v. 15, pp. 12-14.

13 Em especial, temia-se a falta de quadros na colônia para atender às demandas da administração fazendária; em particular, por aqueles que eram providos no cargo "de serventia", interinamente, pelo governador ou pelo capitão-mór, ver AHU/ BA/SÉRIE LUÍSA DA FONSECA/CONSULTA do Conselho Ultramarino; 11 de setembro de 1641 [cx. 8, doc. 932]. Disso resultava que "alguns provedores se valiam de homens de negócio para lhe fazer as contas", do que se esperava prejuízo certo para a Fazenda Real; AHU/BA/SÉRIE LUÍSA DA FONSECA/REQUERIMENTO de João Dias Guedes [cx. 5, doc. 631]. 
Situações extraordinárias, como um ataque estrangeiro e a organização da defesa, eram, até então, administradas pelo empreendimento pessoal e pelo sistema de promessa, requerimento e concessão de mercês. ${ }^{14}$ Foi também nesse espírito que muitos fizeram empréstimos à Coroa, particularmente durante o ataque holandês a Salvador, de 1638. Mas dizia-se também: "padeceríamos grandes perseguições se o dito provedor mór não remediara os ditos mantimentos e algumas pagas de capitães e oficiais com a sua fazenda". ${ }^{15} \mathrm{Na}$ falta de meios com que a Fazenda Real na Bahia quitasse suas dívidas, tudo o que lhe era adiantado passava para a "economia da graça", e era preciso encaminhar à corte pedidos individuais de restituição ou recompensa. Nesses termos, entretanto, jamais teria sido possível que se articulasse um padrão de financiamento para a defesa da Bahia (LENK, 2009), uma vez que grande parte do serviço da Fazenda Real havia dependido do funcionamento desse sistema, sua falha se apresentou como dos próprios oficiais da Fazenda Real. À sua frente, como supervisor e responsável, foi o Provedor-mor quem sofreu as consequências.

Talvez a melhor representação do problema tenha sido o inferno pessoal de Francisco Soares de Abreu, Provedor-mor entre 1629 e 1632, quando foi finalmente suspenso do cargo por Diogo Luís de Oliveira. ${ }^{16}$ Ao chegar a Salvador, já tinha quarenta anos de serviços prestados à

14 Veja-se, por exemplo, o ataque do corsário britânico James Lancaster a Pernambuco, em 1594, ao Recife: o rico escrivão da alfândega, Antônio da Rocha, ofereceu 2.500 cruzados de sua fazenda para o provisionamento dos soldados da defesa de Olinda (JOYCE JR., 1974: 257).

15 AHU/BA/SÉRIE LUÍSA DA FONSECA/CARTA de D. Francisco de Moura Rolim a S.M.; 8 de setembro de 1625 [cx 3, doc. 371].

16 BIBLIOTECA DA AJUDA/CÓDICE 49-X-10/ALVARÁ sobre o tocante a Francisco Soares de Abreu na Fazenda Real do Brasil, 5 de julho de 1629 [fl. 10]. Seu mandato incluía licença para "tomar algumas informações de alguns senhores de engenho da capitania [...] para coisa da obrigação de seu cargo de provedor de minha Fazenda, ou para fazerem o que de minha parte lhes ordenar, os possa mandar ir ante si, e emprazá-los para isso [...] e assim poderá chamar os ministros e mais pessoas da Fazenda e justiça à sua casa, para o dito efeito [...] e que quando o dito Francisco Soares de Abreu os mandar chamar, e requerer pasa que o dite é, acudam a seus mandados e requerimentos, e os cumpram, e guardem sem duvida nem contradição alguma”. 
Coroa, inclusive na Provedoria de Pernambuco (entre 1601 e 1604). ${ }^{17}$ Foi tesoureiro da Ordem de Cristo e, anos depois, seria correspondente direto da Duquesa de Mântua. ${ }^{18} \mathrm{O}$ filho, Cristóvão Soares de Abreu, seria secretário de D. Francisco de Melo. ${ }^{19}$ Seu enorme zelo na obediência aos regimentos colocou-o em desinteligência com os demais ramos da administração colonial, logo que chegou. Nos primeiros meses de trabalho, desentendeu-se com o governador por conta do regime de pagamento dos soldos, que exigia adaptações à nova situação do exército (o pagamento por lista, e não por folha). Soares de Abreu recusava-se a agir de outra forma, que não a do seu regimento. ${ }^{20}$ Por mais necessária que fosse a ordem, tratava-se de uma intromissão no foro do Provedormor da Fazenda Real.

A ofensa foi agravada pela concessão esporádica de livranças a alguns oficiais do presídio, por motivos variados, sem que Francisco Soares de Abreu fosse consultado. ${ }^{21}$ Este, já em novembro de 1629, pedia à Coroa para voltar ao Reino. Dizia que estava doente e, se não viesse logo a licença, "será força largar o ofício, por ser o exercício dele mais oposto a meus achaques que o clima da terra, que não é menos". Queixava-se das "moléstias e vexações que me faz o governador-geral", por não admitir transgressões dos "regimentos, provisões e estilos com que se cobra e despende nesse Reino". Diogo Luís de Oliveira mandava "despender absolutamente como lhe parece, e sem registrar nem mostrar seu regimento", o que "não pode deixar de ser muito embaraço para as contas dos oficiais do recebimento". Grande parte da contabilidade era paralela; receitas e despesas não eram lançadas nos livros. Os oficiais subalternos e o tesoureiro geral não obedeciam ao Provedor-mor:"são muito favorecidos do governador e não fazem mais que o que lhes

17 BIBLIOTECA DA AJUdA/CÓDICE 49-X-10/CARTA de Francisco Soares de Abreu a S.M., 5 de julho de 1629 [fl. 120].

18 BIBLIOTECA DA AJUDA/CÓDICE 49-X-10/CARTA de Francisco Soares de Abreu a S.M., 8 de janeiro de 1630 [fl. 148]; BIBLIOTECA DA AJUDA/CÓDICE 49-X-10/ CARTA régia a Francisco Soares de Abreu, 10 de dezembro de 1638 [fl. 15].

19 BIBLIOTECA DA AJUDA/CÓDICE 49-X-23/CARTA de Francisco Soares de Abreu a S.M., 29 de agosto de 1647 [fl. 358].

20 BIBLIOTECA DA AJUDA/CÓDICE 49-X-10/TRESLADO do assento que se tomou em mesa da Fazenda, 10 de setembro de 1629 [fl.111-15].

21 Ibidem. 
ordena". ${ }^{22}$ Por seguir à risca os regimentos da provedoria, Soares de Abreu colocava-se em situações difíceis. Foi excomungado pelo clero soteropolitano, pois se recusava a lançar, em folha, pagamentos a padres, cuja documentação se havia perdido durante a ocupação de Salvador. Até que pudesse finalmente voltar a Lisboa, Soares de Abreu permaneceria um exilado, quase um prisioneiro.

Jorge da Silva Mascarenhas, que o substituiu na Provedoria, adotou outro estilo: em outubro de 1632, arguia contra a feitura de um livro de receita e despesa, "pela confusão e dano que dele pode resultar". ${ }^{23} \mathrm{Na}-$ turalmente, do ponto de vista formal, ficava sujeito à execução de sua fazenda pessoal pela Casa dos Contos - mas é dificil conceber alguém que tivesse interesse em tanto, muito menos a própria Coroa.

Mascarenhas foi sucedido por Pedro Cadena deVilhasanti em 1635. O Conselho da Fazenda tinha-lhe apreço "pois trata mais do acrescentamento da Fazenda Real do que do seu, pois este zelo é mal quisto". ${ }^{24}$ Também passou poucas e boas à frente da provedoria, particularmente em sua relação com os soldados do exército de Pernambuco, derrotado e retirado para a Bahia a longo de 1637. Depois do ataque do Conde de Nassau a Salvador, teve problemas no pagamentos de soldos aos combatentes que haviam defendido a cidade: "alguns capitães e oficiais maiores, com a espada na mão, me pedem o seu pagamento, fazendo-me cada dia muitas descortesias". ${ }^{25}$ O Conde de Bagnuolo e os administradores da tropa pernambucana adulteravam as listas daquelas companhias, para receber mais rações de carne e farinha. $\mathrm{O}$ bispo ameaçava Vilhasanti de excomunhão, por não lhe pagar o que era devido. Mesmo depois que o Governador, Pedro da Silva, e o Mestre de campo Luís Barbalho interferiram em seu favor, a situação de Vilhasanti continuava ruim:

22 BIBLIOTECA DA AJUDA/CÓDICE 49-X-10/CARTA de Francisco Soares de Abreu a S.M., 29 de novembro de 1629 [fl. 144].

23 Resposta de Jorge da Silva Mascarenhas a Diogo Luís de Oliveira, 21 de outubro de 1632, in DHBN, v. 16, pp. 184-186.

24 AHU/BA/SÉRIE LUÍSA DA FONSECA/CONSULTA do Conselho Ultramarino, 13 de janeiro de 1637 [cx. 9, doc. 894].

25 AHU/BA/SÉRIE LUÍSA DA FONSECA/CARTAS de Pedro Cadena de Vilhasanti a S.M., de 1 a 12 de junho de 1638 [cx. 7, doc 789]. 
[...] nenhuma coisa tem melhoramento, antes cada dia crescem os provimentos e os gastos, e posto que eu sei o remédio que se lhe pudera dar, cortando pelo são, manda-me o governador que dissimule até a vinda da Armada; [...] aqui cada um trata do seu particular, e o serviço de Vossa Majestade e o bem comum o sente; Eu sou fraca figura e com pouca assistência dos superiores para poder remediar estas cousas, que com facilidade se fizera e se a tivera. ${ }^{26}$

Assim como Soares de Abreu, no início de 1639,Vilhasanti foi suspenso do cargo.

Seu sucessor, Sebastião Parvi de Brito, era outro letrado com mais de vinte anos de experiência e longa folha de serviços. Foi o primeiro Ouvidor da repartição do Sul, por quatro anos, no início do século, e Provedor da Fazenda e dos Defuntos. Como os demais, estava sempre à mercê dos "grandes danos e insultos" que a gente de mar e guerra e de terra lhe fazia, quando começava a lhes faltar o sustento. Sua correspondência com Cristóvão Soares de Abreu deixou-nos um rico testemunho dos problemas da Provedoria da Fazenda Real: "os generais e almirantes andaram por mar e terra tomando o que achavam e passando escritos para o provedor-mór os pagar", e os particulares, sem alternativa, aceitavam. ${ }^{27}$ Parvi de Britto lamentava:

Que como, Senhor, se hajam de por penas a quem não tem poder, obrigando-o que faça autos para satisfazer as queixas de muitos e pagar a culpa que não tem, ponham as penas a quem tem e toma todo o poder, como são os generais que se lhe querem fazer requerimentos e protestos, respondem com agravos e descortesias, como se hão feito a muitos provedores-mores, ficando sem abrigo de quem os defenda e os maiores sem repreensão e castigo [...] e manda o general que os capitães e soldados vão à casa do provedor-mór, lhes dê sustento, e senão tire de sua casa.

Que a verdade é, Senhor, que em necessidades não há leis, nem súdito que possa resistir ao superior, tão supremo de poder e potência para o

\footnotetext{
26 AHU/BA/SÉRIE LUÍSA DA FONSECA/CARTA de Pedro Cadena de Vilhasanti a S.M., 3 de novembro de 1638 [cx. 7, doc. 803] - grifo nosso.

27 BIBLIOTECA DA AJUDA/CÓDICE 51-VI-21/CARTA de Sebastião Parvi de Brito a S.M., 3 de fevereiro de 1641 [fls. 294-308].
} 
que querem mandar; e quando menos, mandam aos oficiais e almoxarifes não despendam nem paguem nada sem ordem sua, como de presente está feito. ${ }^{28}$

Necessitas legem vincit. Maquiavel predicava que "não pode haver boas leis onde não há um bom exército, e onde haja um bom exército é conveniente que haja boas leis". Para Sebastião Parvi de Brito, a Fazenda Real na Bahia seria beneficiada por uma reforma em suas normas de funcionamento. Em primeiro lugar, sugeria a valorização dos serviços de tesouraria. ${ }^{29}$ Em segundo lugar, que tais cargos não fossem ocupados por moradores da colônia, pois teriam "temor de levar consigo as contas" e responder por elas pessoalmente nos tribunais do Reino, onde também haveria de estar resguardado das retaliações dos governadores, seriam mais bem preservadas as disposições do regimento e "com este temor se ordenarão as coisas melhor" ${ }^{30}$ Parvi de Brito tinha esperança de que o recém-chegado Vice-Rei do Brasil pudesse melhorar a situação de todos. De fato, o Marquês de Montalvão ordenou que todos os lançamentos da Fazenda Real, na Bahia, se fizessem em livros de receita e despesa, à maneira dos armazéns do Reino, mas a resistência era geral. Logo que foi deposto, a ordem foi cancelada pelos governadores da junta, "sem quererem que houvessem [sic] clareza em tudo que se despendia, no que ela [a junta] recebeu dinheiro muito grande". ${ }^{31}$ Não seria tão cedo que as contas da Fazenda Real na Bahia receberiam tratamento idôneo - nem seria a idoneidade, portanto, a dirimir as tensões políticas em redor da carga tributária.

\footnotetext{
28 Ibidem.

29 “O mais importante ofício que hoje há naquela praça é o de tesoureiro geral, e pagam-lhe pelas grandes quantidades de dinheiro e outros efeitos que da Fazenda de Vossa Majestade recebe, em muitas ocupações e contínuas e com tão pequeno ordenado que não há quem queira servir e aceitar tal cargo" (Ibidem).

30 Ibidem.

31 AHU/BA/SÉRIE LUÍSA DA FONSECA/CONSULTA do Conselho da Fazenda, 20 de novembro de 1643 [cx. 9, doc. 1020].
} 


\section{A "suavidade" no fisco e a Câmara de Salvador}

A partir da Restauração de 1640, a aclamação de D. João IV na Bahia e a deposição do Marquês de Montalvão do Governo Geral, a linha adotada pela administração colonial seria inteiramente oposta àquela receita de retidão e zelo pela norma. Prevaleceria a orientação geral de busca de "meios suaves": a flexibilização de provisões, o reconhecimento das sensibilidades políticas da colônia e a composição com seus setores dominantes. Para evitar conflitos, "se deseja toda a suavidade com que ao povo lhe fique mais fácil", ou que "o povo receba sem clamor". ${ }^{32}$ Tal orientação tornou-se especialmente importante naquela década, uma vez que a substituição dos direitos de Angola e da imposição dos vinhos (cuja arrecadação diminuiu) pela vintena da produção baiana e dos donativos extraordinários significou o grande aumento na tributação direta, em razão dos impostos indiretos. Mas tributos diretos são visíveis, não se escondem na elevação dos preços, portanto, essa não era a fonte mais "suave" de receita - era a única disponível. A par de tudo, graças à constante notícia do "estado miserável" da praça e do quanto seus moradores despendiam de suas fazendas nas vintenas e donativos, D. João IV e o Conselho Ultramarino, certamente, tinham ideia da sensibilidade da situação. Sendo assim, a política de "suavidade" haveria de compensar, por outros meios, a "brutalidade" da tributação direta, sem que fosse alterada.

A escolha da Câmara como interlocutora foi um dos elementos dessa diretriz. Desde 1638, pelo menos, os oficiais da vereação tentavam explorar a tributação extraordinária como meio de ampliar sua estatura política. ${ }^{33}$ A mais conhecida de suas conquistas foi a outorga dos privilégios do Porto a Salvador, em 1646. ${ }^{34}$ Outra de tais concessões foi o afrouxamento da fiscalização do comércio de açúcar no porto, pelo qual a Câmara e outras freguesias do Recôncavo combateram com tenacidade. Por demanda dos mercadores, que havia muito se queixavam do engodo no peso das caixas de açúcar, a Coroa instituiu, em 1644, um

Ata da Câmara de Salvador, 8 de junho de 1639 (DHAM: AC, v. 1, pp. 405-406).

Ata da Câmara de Salvador, 17 de julho de 1638 (DHAM: AC, v. 1, p. 368).

34 ARQUIVO NACIONAL DA TORRE DO TOMBO/CHANCELARIAS RÉGIAS/D. JOÃO IV/DOAÇÕES/MERCÊ dos privilégios da cidade do Porto à cidade de Salvador, 22 de março de 1646 [lv. 19, fl. 122]. 
novo juizado para as balanças do porto de Salvador. A Câmara reagiu, afirmando, acintosamente, que os moradores não tinham culpa se os marinheiros "costumam abrir as caixas e tirar o açúcar delas, e abaixá-las e tornarem a pregar". ${ }^{35}$ Para evitar o conflito, a Coroa terminou por aceitar essa explicação, revogando a provisão que criava aquele cargo.

No que toca à tributação, tal "suavidade" não se referia apenas a compensações que a Coroa oferecia para os moradores da Bahia em conjunto, pois, ainda que não houvesse alternativa ao sustento do exército, senão pela riqueza da capitania, não estava excluída a redistribuição da carga fiscal entre setores sociais específicos. Nesse sentido, a Câmara se destacava como espaço político, por sua maior permeabilidade à estrutura de poder e às tensões que dela resultavam. Desse modo, o Senado foi importante como meio de confronto e composição política entre setores do senhoriato colonial pelos rumos da fiscalidade. Em última instância, o objetivo da Coroa e de seus oficiais, ao abrirem o processo decisório à Câmara, era não estimular e não se comprometer, desnecessariamente, com os embates produzidos pela carga tributária, salvo quando fosse de seu interesse imediato.

Assim, D. João agradeceu aos moradores por oferecerem a vintena, e não foi mais servido se interessar pela forma como como se fariam as cobranças. Ao contrário do zelo idôneo pela contabilidade, o que se verificou foi a predominância da informalidade e da sonegação dos mais poderosos. Durante a ocupação de Itaparica por Von Schkoppe, o governo buscou informação do quanto a Câmara arrecadava, mas não conseguiu, "pela confusão dos livros em que se lançou a vintena" e a imposição dos vinhos. Sabia-se apenas que a vintena levantava o pior do açúcar, da farinha e de mais gêneros que se poderiam conseguir, e muito ainda estava por cobrar. ${ }^{36}$ Nos donativos extraordinários, a "suavidade" implicava em descasamentos vários: cada freguesia pagava quando podia ou bem lhe entendia, e a grande maioria atrasava. ${ }^{37}$ Depois de 1647 , constatou-se que as listas de cobrança estavam obsoletas, e a

\footnotetext{
35 AHU/BA/SÉRIE LUÍSA DA FONSECA/CONSULTA do Conselho Ultramarino, 26 de agosto de 1645 [cx. 10, doc. 1138].

36 AHU/BA/SÉRIE LUÍSA DA FONSECA/CARTA da Câmara de Salvador a S.M., 7 de janeiro de 1648 [cx. 11, doc. 1282].

37 Ata da Câmara de Salvador, 8 de junho de 1639, e atas seguintes (DHAM: AC, v. 1, pp. 405 e segs.).
} 
coleta ficava muito dificil. ${ }^{38}$ Como averiguou o Desembargador Salema de Carvalho, anos depois, "o povo diz, e os pobres se queixam, vendo que os ricos, uns pagam pouco e outros nada, com que se acomodaram alguns dos poderosos a também não darem". ${ }^{39}$ Os oficiais da Câmara lucravam no paralelo, vendendo o açúcar abaixo do valor. Mais do que isso: "os cobradores das freguesias, que são os poderosos, com parte do que cobraram no primeiro ano ainda na mão" (nunca haviam pago, portanto); por outro lado, "os que foram cobrar por fora, levando aos homens mais dinheiro do que deviam, sem lhe quererem dar quitação, lho tornam a pedir segunda vez, não lhe valendo justificar como o tem pago". ${ }^{40}$

A criação da Companhia Geral de Comércio do Brasil, no início de 1649, seria o maior dos testes para essa política de coadunação da fiscalidade com os setores dominantes do senhoriato colonial. Com o regime de frotas, a elevação do preço dos fretes e o monopólio dos quatro maiores gêneros de importação, D. João IV transferia para a colônia o ônus do financiamento da reconstrução do poder naval português. Salvador já havia combatido o regimento da frota de Salvador Correia de Sá, em 1644, por motivos semelhantes. O aumento repentino do custo de vida, em 1650, reascendeu a cizânia. O contrato de instituição da Companhia fixava os preços, no Brasil, para os produtos de seu estanco, "todos mui levantados". ${ }^{41}$ Com isso, reduzia-se a renda real da colônia, já sobrecarregada pela tributação, de maneira que se recolocava a necessidade de reorganização do fisco para atender às necessidades do exército em Salvador.

Com o aumento dos preços do vinho, especificamente, a Companhia Geral havia removido uma parte importante da base tributária da Câmara. Desde meados de 1642, esse comércio havia decrescido significativamente. O preço da canada, no varejo, era de $\$ 640$ em 1640, com

\footnotetext{
38 Ata da Câmara de Salvador, 1 de agosto de 1650 (DHAM: AC, v. 3, pp. 88-94).

39 AHU/BA/SÉRIE LUÍSA DA FONSECA/CONSULTA do Conselho Ultramarino, 12 de outubro de 1655 [cx. 13, doc. 1610].

40 Ibidem.

41 Ata da Câmara de Salvador, 02 de setembro de 1649 (DHAM:AC, v. 3, pp. 37-38);Ata da Câmara de Salvador, 22 de março de 1650 (DHAM:AC, v. 3, pp. 68-69). ARQUIVO HISTÓRICO MUNICIPAL DE SALVADOR (AHMS)/PROVISÕES RÉGIAS/CARTA DE S.M. à Câmara de Salvador, 26 de outubro de 1649 [1v. 2, fl. 17].
} 
todas as imposições, velha e nova; em momentos de maior escassez, porém, podia chegar a cinco ou seis patacas (1\$600 a 1\$920). Em 1644, como o comércio continuara a encolher, o total de tributos em cada pipa foi reduzido de $15 \$ 400$ para $7 \$ 000 .^{42}$ Em 1646, proibiu-se o comércio de aguardente, porquanto as imposições do vinho "rendiam a metade menos do que dantes costumavam render", e aumentou-se o imposto para $7 \$ 500 .{ }^{43} \mathrm{~A}$ frota da Companhia Geral, entretanto, chegou a Salvador com determinação para vender a canada a dois cruzados $(\$ 800)$, que pagariam $4 \$ 000$ de imposições e $4 \$ 000$ para o taverneiro sobre os $40 \$ 000$ do preço da pipa no atacado. O Conde de Castelo-Melhor, Governador do Brasil, ordenou que se pagasse a imposição sem alterações. Mas o regime de monopólio havia reduzido em muito o volume do comércio; sobretudo porque passaram a predominar os péssimos vinhos do Reino e de São Jorge, que, ademais, pagavam apenas $3 \$ 000$ de tributo, segundo as posturas anteriores. Sendo assim, a Câmara teria de cobrir a falta na imposição com novos donativos, ou com a melhor arrecadação das vintenas. ${ }^{44}$ Em junho, a Câmara nomeava um administrador e um contador, para reorganizarem a arrecadação e tentarem corrigir os problemas dos anos anteriores. ${ }^{45}$

Assim, o que aconteceu, em julho e agosto de 1650, foi uma reação daqueles que sustentavam a carga tributária, que se havia tornado insustentável pela soma da má distribuição dos tributos com a exploração pela Companhia Geral. Em reunião com sessenta e sete presenças, a Câmara, então, pediu o fim da cobrança da vintena, pela "carga dela, e desigualdade, e pouco fruto que sua renda dá para ajuda dos terços e presídio desta praça". Menciona-se a dificuldade dos senhores de engenho em mantê-los a produzir. Acima de tudo, porém, estava a denúncia da desigualdade na arrecadação ${ }^{46}$ : "há produtores que pagam

42 AHU/BA/SÉRIE LUÍSA DA FONSECA/CARTA de Antônio Teles da Silva a S.M., 23 de setembro de 1642 [cx. 8, doc. 976].

43 AHU/BA/SÉRIE LUÍSA DA FONSECA/CARTA de Antônio Teles da Silva a S.M., 5 de novembro de 1646 [cx. 11, doc. 1240]; Ata da Câmara de Salvador, 25 de outubro de 1646 (DHAM: AC, v. 2, p. 321). Na mesma ocasião, passaram a coletar uma imposição sobre a canada de azeite de $\$ 400$.

44 Ata da Câmara de Salvador, 24 de março de 1650 (DHAM: AC, v. 3, pp. 70-74).

45 Ata da Câmara de Salvador, 4 de junho de 1650 (DHAM: AC, v. 3, pp. 74-76).

46 Diziam que o donativo da vintena não era "nem seguro, nem certo, e, sobretudo, desigual" (Ata da Câmara de Salvador, 1 de agosto de 1650, DHAM:AC, v. 3, pp. 88-94). 
até 600,500,400,200 e 100 mil réis, que não tem, enquanto há homens de maior cabedal desta praça que não pagam mais que três mil". Queixavam-se do "grande dano dos muitos hábitos, foros, familiares, sargentos-mores, tenentes, capitães e outros que, por muito ricos, se tem introduzido em os mesmos privilégios"; também da vasta propriedade de clérigos e ordens religiosas. "Assim ficam pagando os pobres e os engenhos e lavradores não o que era razão como se mostra senão do que devem e metem no fornecimento". Pediam que a vintena fosse substituída por um novo aumento na imposição dos vinhos, que era cobrado de forma "tão igual que não há privilégio que isente de pagar, nem poderoso que o fique devendo". ${ }^{47}$

Diante disso, Castelo-Melhor reuniu-se com os oficiais da Câmara, mais o bispo, os ministros da Fazenda e Justiça, os homens principais do governo da Bahia, e ordenou que votassem livremente o que sentiam sobre a matéria. Só os administradores da Junta da Companhia Geral discordaram. A imposição do vinho aumentou e a vintena foi suspensa. O preço da canada iria a $\$ 960$, com dez reais de incremento na renda do taverneiro e $\$ 150$ para a infantaria da cidade; com o que o tributo exigido por pipa passava de $4 \$ 000$ a $13 \$ 000 .{ }^{48}$ Além disso, atendia-se à fiscalização da cobrança, instituindo que quaisquer pipas de vinho que viessem nas armadas não se poderiam vender, "sem primeiro serem varejadas por um dos juízes e vereadores desta Câmara, com o escrivão dela, que hão de assistir ao dito varejo nas lojas onde estiverem recolhidas". As punições para a abertura e o varejo de uma pipa de vinho sem passagem pela Câmara seriam multa de $200 \$ 000$ e dois anos de degredo em Angola (seis, para os pobres). ${ }^{49}$

No início de 1651, chegavam a Salvador notícias de Recife: Francisco Barreto pedia ajuda à capital, porque "de Lisboa não tem chegado embarcação alguma". ${ }^{50}$ Castelo-Melhor solicitava à Câmara um "novo meio suave" de se tirar mantimentos para o presídio, que estava mal pago, e para o exército de Pernambuco.Articulava-se uma finta para recolher

\footnotetext{
47 Ata da Câmara de Salvador, 1 de agosto de 1650 (DHAM: AC, v. 3, pp. 88-94).

48 Ata da Câmara de Salvador, 17 de outubro de 1650 (DHAM: AC, v. 3, pp. 95-98).

49 Ata da Câmara de Salvador, 22 de outubro de 1650 (DHAM: AC, v. 3, pp. 98-100).

50 Carta de Francisco Barreto à Câmara de Salvador, 4 de maio de 1651 (DHAM: AC, v. 3, pp. 143-146).
} 
mil cabeças de gado. ${ }^{51}$ Nesse momento, chegou o correio da Coroa, ordenando o reestabelecimento da vintena e o fim da nova imposição do vinho, e "se não alterar o que primeiro ajustou o povo com a Companhia Geral". Os administradores haviam dito ao monarca que

[...] logo que a frota da armada saiu desse porto algumas pessoas de maior sujeito dessa cidade haviam induzido os oficiais da Câmara dela a aliviarem, como aliviaram, aos moradores da terra do donativo das vintenas [...] sobrecarregando os vinhos, que é um dos principais gêneros da Companhia, além da imposição antiga. ${ }^{52}$

Além disso, a Coroa tinha notícia de que se procedia "com grande omissão e descuido" na extinção do vinho de mel, da aguardente e da cachaça, a despeito das "graves penas" que havia instituído para tais delitos no Capítulo 35 da Instituição da Companhia Geral. ${ }^{53}$ Portanto, além de reinstaurar as vintenas, D. João ordenava que se cumprisse a extinção da aguardente e que "façam averiguar as culpas das pessoas que andaram inquietando o povo e vos forem apontados pelos administradores da Companhia Geral que aí residem e me aviseis delas". ${ }^{54}$

Com os moradores reunidos para a leitura das cartas, um juiz ordinário da Câmara afirmou que cumpriria qualquer ordem do rei, mesmo em prejuízo de sua fazenda ou até de sua vida, mas não aquela. Segundo ele, era sinistra a informação que a Coroa recebia dos homens da Companhia Geral, pois a vintena causava prejuízo ao erário régio, e havia-se decidido por sua extinção "não por indução ou persuasão nenhuma". ${ }^{55}$ Acusava-se a opressão que sobre aqueles vassalos exercia a Companhia Geral.A primeira frota havia reduzido o comércio de vinho a 1.500 pipas; com a segunda, estava estrangulado a não mais que 500 . Segundo a Câmara,

\footnotetext{
51 Ata da Câmara de Salvador. 28 de abril de 1651 (DHAM: AC, v. 3, pp. 148-149).

52 AHMS/PROVISÕES RÉGIAS/CARTA DE S.M. à Câmara de Salvador, 7 de fevereiro de 1651 [lv. 2, fl.26].

53 Provisão real de 13 de setembro de 1649 (CCLP, 1649, pp. 50-51).

54 Cartas de S.M. à Câmara de Salvador, (DHAM:AC, v. 3, pp. 156-158); AHU/BA/SÉRIE LUÍSA DA FONSECA/CARTAS DE S.M. à Câmara de Salvador, janeiro de 1651 [cx. 11, doc. 1387, 1388].

55 Ata da Câmara de Salvador, 02 de junho de 1651 (DHAM: AC, v. 3, pp. 150-154).
} 
[...] o dinheiro que anda nesta praça, o mais dele se gasta nos quatro gêneros do estanco da Companhia e todo vai às mãos e poder dos ditos administradores [...] que senhores de todo o dinheiro compram os ditos açúcares por preços mui diminutos, com grande comodidade sua e natural perda e diminuição da Fazenda Real. ${ }^{56}$

\section{O argumento colocava a Coroa em má posição:}

[...] como isto foi um donativo que o povo impôs sobre si, fica sempre a disposição do dito povo que, por serviço de Sua Majestade o quis impor, e não há duvida que podia consignar e impor esta quantia em outro gênero, pois sempre impunha sobre si [...] foi justo que se impusesse o donativo nos vinhos e se tirasse a vintena pois este era o remédio mais suave que se achava. $^{57}$

Se tais haviam sido os termos da relação entre a Coroa e a Câmara, não seria agora que haveriam de mudar.

É importante notar que a desobediência da Câmara foi endossada tanto pelo governador como pelo Conselho Ultramarino, em consideração do que era mais conveniente à Coroa, apesar dos despachos de $\mathrm{D}$. João. É muito pouco plausível que a Câmara tivesse meios para desviar esses quadros do interesse da monarquia, em favor de si própria. $\mathrm{O}$ Governador Geral do Brasil, D. João Rodrigues de Vasconcellos, foi largamente favorável à Câmara, a despeito das cartas régias. Em sua correspondência, dava notícia de como era o regime de frotas que havia desabastecido a Bahia, empobrecido o valor do açúcar e encarecido os gêneros do estanco, com o que ficava mais difícil o custeio do presídio (COSTA, 2002:543). Sua biografia, entretanto, não nos permite considerar que agia sem qualquer consideração pelo interesse da Coroa.$^{58} \mathrm{Nem}$

56 Ata da Câmara de Salvador, 14 de junho de 1651 (DHAM: AC, v. 3, pp. 158-167).

57

58 O segundo conde de Castelo-Melhor, D. João Rodrigues de Vasconcelos, era um exemplo eloquente de lealdade. Em 1641, quando soube da aclamação de D. João IV, estava em Cartagena com um destacamento da força que havia atacado Recife, no ano anterior. Junto a D. Rodrigo Lobo e Pedro Jaques de Magalhães, teria armado uma conjura para sequestrar os galeões do porto e reunir-se à frota de Dias Pimenta, um general que, ao cabo, permaneceria fiel a D. Filipe. Pela suspeita de conspiração, Castelo-Melhor foi preso e enviado a ferros para julgamento em Castela (apesar da intervenção da irmã do almirante espanhol, D. Ana, com quem tinha uma amizade 
seria punido por tal opção: pelo contrário, a casa de Castelo-Melhor estava em franca ascendência, e seu filho viria a ser o valido de Afonso VI.

O Conselho Ultramarino confiava no julgamento do governador e, com o tempo, também se oporia à Companhia Geral no tocante à imposição dos vinhos. Desde que D. João havia repreendido a Câmara de Salvador em sua correspondência, os membros daquele Conselho não acreditavam que fosse essa a melhor política. Responderam ao monarca com "algumas razões que se oferecem para a resolução de Vossa Majestade se moderar em parte". Principalmente, achavam que se devia rever a ordem de prisão aos cabecilhas do movimento: "causará geral e notável sentimento em todos aqueles moradores". Não havia motivo para questionar as decisões de Castelo-Melhor, "um tal governador, e tão zeloso". Entendiam que a Companhia poderia repassar a nova imposição aos moradores sem dificuldade, nem se haveria de esperar o contrário. Ademais, tudo convinha para o sustento da infantaria. Com isso, o Conselho recomendava à Coroa que fosse condescendente com as decisões da Câmara de Salvador e, com a outra mão, escrevesse aos governadores da Bahia e do Rio de Janeiro, e ao Mestre de campo geral em Pernambuco, "que em tudo façam cumprir e guardar inviolavelmente as condições do assento, e que também vigie, sobre que os administradores de sua parte também façam o mesmo". ${ }^{59}$

Vale notar que as tensões resultantes do regime de monopólio e de navegação em frota levaram, em primeiro lugar, a uma revolta contra a tributação - portanto, a um conflito predominantemente interno aos senhores da colônia. Assim, em paralelo à disputa entre produção e comércio (tanto no campo da formação de preços como na distribuição da carga tributária), corria a disputa entre "pobres" e "ricos e poderosos" (como eram citados) pela distribuição do fardo fiscal. A bem da verdade, uma disputa resultante dos privilégios formais (as isenções tributárias) e informais (o acesso ao descaminho de tributos, o poder paralelo), que sobrecarregavam os setores desprivilegiados da classe senhorial. Ambas

toda especial). Uma vez na península, foi resgatado por corsários holandeses, por encomenda de D. João IV (Vasconcelos, 1874).

Segundo o Conselho, a imposição "não vem a ser dano algum seu (para a Companhia), o que sobre elas mais se carregar, pois o vem a pagar aqueles moradores, e não é para outrem”. AHU/BA/SÉRIE LUÍSA DA FONSECA/CONSULTA do Conselho Ultramarino, 26 de janeiro de 1651 [cx. 11, doc. 1387]. 
as disputas pautaram a política soteropolitana a partir de 1649; a mesma vintena que era atacada pelos senhores "pobres" da Bahia era do interesse, ainda que marginal, tanto dos setores privilegiados como da Companhia Geral. Mas é razoável supor que tal disposição de forças facilitava a posição do governo, pois afastava uma polarização como a que ocorrera irreversivelmente em Pernambuco, após a partida do Conde de Nassau, e que havia comprometido a segurança do Brasil holandês. Imagine-se, com todas as devidas ressalvas à contrafactualidade, se o Governo Geral ou o comando do exército em Salvador estivesse às ordens da Junta da Companhia Geral. Quando se apostava na "suavidade" do governo da colônia - o que vimos no governo de Portugal, no Conselho Ultramarino, no Governo Geral e até na Câmara de Salvador - os quadros dirigentes do Império mostravam ter, no mínimo, uma percepção de tais problemas.

Ao mesmo tempo, a reação dos senhores prejudicados pela tributação não conseguiu resolver aquelas desigualdes. A falta de vinhos seria a regra naquela década, de modo que o fisco não poderia prescindir das fintas e donativos, meios extraordinários de tributação direta, cuja cobrança era tão problemática quanto a da vintena. Até 1651, ainda se cobravam os quartéis do dinheiro coletado para a armada de D. Antônio Teles de Meneses, de três anos antes. Em 1652, foi necessário levantar uma finta de 8:000\$000, ao se constatar que a imposição dos vinhos não substituía a vintena suspendida. ${ }^{60} \mathrm{O}$ mesmo aconteceria nos anos seguintes: "se obrigam os oficiais da câmara a satisfazer o que faltar e tornam a pagar à sua conta", mediante os donativos extraordinários. ${ }^{61}$ Vale dizer, os problemas da arrecadação da vintena não foram resolvidos, apenas suavizados. Reduzia-se o montante cobrado, de 5\% fixos para apenas o necessário para cobrir o déficit anual. Mas continuava o recurso àquela forma de tributação direta, que chamariam de fintas ou "lançamentos" da vintena, onde, certamente, permaneceriam os abusos e a desigualdade.

Todavia, a repactuação da fiscalidade na década de 1650 também incluiu um mecanismo importante a suavizar a carga tributária para o

\footnotetext{
60 Ata da Câmara de Salvador, 23 de setembro de 1651 (DHAM:AC, v. 3, pp. 176-178).

61 AHU/BA/SÉRIE LUÍSA DA FONSECA/CONSULTA do Conselho Ultramarino, 20 de julho de 1654 [cx. 13, doc. 1557].
} 
Recôncavo baiano. Em junho de 1652, a Câmara queixava-se de que, para os gastos da infantaria, "vem a ser a Fazenda Real a ser a que dispende a menor parte e a do povo a quem, por meio de suas imposições e donativos e contribuições, as supre tudo o que falta para se ajustarem os efeitos com as despesas". Por mais uma vez, a frota da Companhia se havia mostrado pobre, e o governador era levado a solicitar donativos à Câmara. Dessa vez, diante da negativa, Castelo-Melhor ofereceu à Câmara ("para os aquietar") a responsabilidade pelo pagamento dos soldos e mais as despesas extraordinárias, ficando a Fazenda Real apenas com o pagamento das folhas do Estado. ${ }^{62}$ Segundo Pedro Puntoni, tratava-se de um blefe; uma tentativa do Provedor-mor, Simão Álvares de la Penha, de anular as pressões que vinha recebendo de setores da população. ${ }^{63}$ Não eram todos na Câmara a favor da proposta: suspeitavam do que haveria de entrar sob a rubrica das "despesas extraordinárias", ou que acabariam com a folha de soldos atrasados sobre si. Porém, aceitaram a oferta, pois

[...] correndo pelo povo a despesa do que der, será o povo molestado pelo mesmo povo, e terá a liberdade de falar com a verdade e respeito e alegar sua justiça ou queixar-se da sem razão, porquanto então ofende-se a si e não aos ministros.

Para tanto, a Câmara colocou seus termos: receberia os rendimentos do estanco do sal e do direito no embarque do açúcar, que pertenciam à Fazenda Real, e cessaria o repasse da terça parte das rendas à Coroa. Sobretudo, a Câmara solicitou administrar o contrato de fornecimento de farinha de mandioca das vilas de Cairu, Boipeba e Camamu. ${ }^{64} \mathrm{Com}$ o termo assinado no dia 15 de julho, ela passou a fazer à infantaria os

62 BNL/MANUSCRITOS/INFORMAÇÃO sobre o Estado do Brasil, 15 de novembro de 1652 [mss. 218, n. 134].

63 Puntoni, op. cit., 2008.

64 Além disso, a Câmara pedia sargentos e ajudantes do presídio para colaborar nas cobranças; que o pagamento dos terços fosse feito em mostra, com as listas passadas pelo provedor-mor; que tivessem apoio do governador para a cobrança de todas as dívidas e os tributos com a Câmara, "indepentente de qualidade e condição"; por fim, pediam a quitação de uma dívida da Fazenda Real com a Câmara, de 12.000 cruzados. Ata da Câmara de Salvador, 15 de julho de 1652 (DHAM:AC, v. 3, pp. 216-220). 
pagamentos de socorros em dinheiro e mantimentos. O fardamento continuou a correr pela Fazenda Real, que continuava a receber os dízimos e a renda das baleias. ${ }^{65}$

De acordo com os termos da negociação entre a Câmara e CasteloMelhor, é bem plausível que já houvesse algum contrato com as vilas do sul, estabelecendo quantidades e preços para a "farinha de guerra". Talvez alguém, na Câmara, já estivesse por algum tempo com os olhos sobre esse contrato: meses antes, dera-se início à construção do celeiro da cidade, onde haveriam de se armazenar até 12.000 sírios de farinha. ${ }^{66}$ Por outro lado, o acordo não pareceu favorável aos vereadores, de início: "ouvi dizer que eles estavam arrependidos de tomarem sobre si aquela carga, e que queriam antes dar as fintas". ${ }^{67}$ Em pelo menos uma ocasião, pode-se ver a herança dos problemas que o Provedor-mor havia enfrentado, anos antes; as pressões de oficiais do comando do exército para receber seus ordenados, segundo seus termos. ${ }^{68} \mathrm{O}$ que parece, de fato, marcante é que a Câmara se mostraria mais pronta do controle sobre o fornecimento de víveres, determinando contratos de exclusividade, fixando e rebaixando os preços ao produtor. Ao longo de 1653, fechou-se a oferta de gado a quatro marchantes; o peixe ficou com dois mercadores; o porco ficou restrito a um fornecedor. Finalmente, nomeou-se o "recebedor" das farinhas das vilas do sul (alguém que fosse "abonado"), para as recolher ao celeiro da Câmara, onde se poderiam vender "livremente". ${ }^{69}$ Fixaram-se os preços nas vilas e os fretes até Salvador; a administração caberia às Câmaras da capital e de Boipeba. ${ }^{70} \mathrm{~A}$ relação entre ambas, entretanto, não seria horizontal.

Ao longo do tempo, o "conchavo das farinhas" viria a se consolidar como um contrato bastante prejudicial para as vilas de Boipeba, Cairu e Camamu. De acordo com o Termo de 15 de julho de 1652, se hou-

65 Termo assinado pela Câmara com o governador, 15 de julho de 1652 (DHAM: AC, v. 3, pp. 220-225).

66 Ata da Câmara de Salvador, 1 de setembro de 1651 (DHAM: AC, v. 3, pp. 171-175).

67 BNL/MANUSCRITOS/INFORMAÇÃO sobre o Estado do Brasil, 15 de novembro de 1652 [mss. 218, n. 134].

68 AHU/BA/SÉRIE LUÍSA DA FONSECA/CARTA da Câmara de Salvador a S.M., 15 de setembro de 1659 [cx. 15, doc. 1744].

69 Ata da Câmara de Salvador, 8 de março de 1653 (DHAM: AC, v. 3, pp. 235-5).

70 Ata da Câmara de Salvador, 7 de agosto de 1653 (DHAM: AC, v. 3, pp. 251-252). 
vesse falta da parte das vilas, "sempre Vossa Excelência no-lo fará bem obrigando-os a isso, para que se cumpra como se faz até agora”. A defesa dos recebedores da Câmara pelo governador seria testada já em 1654, quando o Conde de Atouguia ordenou que um destacamento de oficiais do governo fosse a Boipeba e Cairu para garantir que ninguém, além da Câmara de Salvador, comprasse farinhas, até que a encomenda de 8.000 sírios estivesse atendida. Um dos encarregados era o ex-capitãomor de Ilhéus, Gaspar Tourinho Maciel (DIAS, 2007:108). Por décadas adiante, a predominância de Salvador em dar os termos do "conchavo das farinhas" estaria sempre secundada pela guarnição do forte no Morro de São Paulo, que tinha ordens dos governadores para atender, prontamente, às necessidades do "comissário" soteropolitano. Desse modo, seria possível à Câmara de Salvador determinar preços e excluir atravessadores do seu negócio, ou mesmo atrasar os pagamentos ao produtor. ${ }^{71}$ Com isso, não apenas se reduzia o preço da farinha para a infantaria, como se garantia a exclusividade no varejo da capital. Anos depois, a Câmara assumiria que levava 100\% de avanço nas farinhas do "conchavo". ${ }^{72}$ Para o produtor de farinha de mandioca, a relação com o governo colonial estava muito longe de ser "suave".

Com isso, chega-se a compreender os termos com que se havia renovado o pacto colonial na Bahia, em favor da preservação do Império português. Não sem um preço, é verdade: para além da tutela militar da metrópole, permitiu-se a permeabilidade dos órgãos de governo por grupos de interesse da colônia, um fato já amplamente reconhecido. Mas um preço ínfimo, diante da importância da exploração do comércio do Brasil para a sobrevivência da autonomia de Portugal. Lembre-se, ademais, que os mesmos grupos de interesse que se encastelaram no governo eram agentes do processo de colonização e sócios do capital comercial na exploração do trabalho escravo. Sua presença na administração contribuía para a reprodução do sistema. Antônio Vieira disse,

\footnotetext{
71 "O procedimento da cobrança de farinha junto aos produtores, por sua vez, apresenta-se na documentação como uma tarefa que se investia de muita tensão, devido à resistência dos moradores em cumprir os termos do contrato. Todavia, os juízes comissários [apontados em Salvador] tinham o respaldo de soldados do Morro de São Paulo para promover as cobranças” (Dias, 2007: 111).

72 Pedro Puntoni. "O conchavo da farinha”, op. cit.
} 
certa vez:"quem diz Brasil diz açúcar, e o açúcar é a cabeça deste corpo místico que é o Brasil" (HANSEN, 2004:132).

Não é a outra coisa que se refere Antonil (2001:334):

Pelo que temos dito até agora, não haverá quem possa duvidar de ser hoje o Brasil a melhor e mais útil Conquista, assim para a fazenda real como para o bem público, de quantas outras conta o Reino de Portugal, atendendo ao muito que cada ano sai destes portos, que são minas certas e abundantemente rendosas. E se assim é, quem duvida também que este tão grande e contínuo emolumento merece justamente lograr o favor de Sua Majestade e de todos os seus ministros no despacho das petições que oferecem, e na aceitação dos meios que, para alívio e conveniência dos moradores, as Câmaras deste Estado humildemente propõem? Se os senhores de engenho e os lavradores de açúcar e do tabaco são os que mais promovem um lucro tão estimável, parece que merecem mais que os outros preferir no favor e achar em todos os tribunais aquela pronta expedição que atalha as dilações dos requerimentos e o enfado e os gastos de prolongadas demandas.

Francisco Barreto, Governador do Brasil, depois de comandar a restauração de Pernambuco, preferia usar outras palavras, o que, com Antonil, aparece em panegírico, no despacho confidencial do governador, ganha algo de cinismo, certamente pragmático. Ocorre que, em 1659, se continuava a debater sobre a conveniência das aguardentes, ou de sua proibição, para o serviço da Coroa. Os argumentos de praxe foram convocados, por ambos os lados. A favor da cachaça, porém, houve aquele que a defendeu por ser popular entre o colono humilde. Mas o governador encontrava pouca utilidade nisso:

[...] não é razão política a que estas [as cachaças] tem contra si, de padecerem muitos pobres na sua falta: porque as Repúblicas se não conservam com os pobres (que nesta podem ter outros exercícios mais úteis); se não com os ricos, que as fazem opulentas. E nesta praça se está vendo que só sobre os ricos cai todo o peso das fintas, e a exceção com que se cobram os faz descompor, por serem comumente quando não tem valor algum dos seus frutos, malbaratando-os antes de os lavrarem, ou vendendo seus escravos, com que se atrasam e impossibilitam invariavelmente os cabedais. E não é conveniente destruir os que conservam as praças por preservar os que as debilitam, e muito menos permitir nestes dois gêneros, que arruínam; podendo lograr com interesse comum do Reino e do Estado aquele de 
que tanta dependência tem o negócio, que a aumenta, e os soldados que a seguram. ${ }^{73}$

\section{Referências bibliográficas}

ALBUQUERQUE, Cleonir Xavier de. A remuneração de serviços da guerra holandesa, Recife: UFPE, 1968.

ANTONIL, André João. Cultura e opulência do Brasil por suas drogas e minas. Lisboa: Comissão Nacional para a Comissão dos Descobrimentos Portugueses, 2001.

BOXER, Charles R. The golden age of Brazil. Berkeley: Univ. of California, 1962.

Portuguese society in the tropics: the municipal councils of Goa, Macao, Bahia and Luanda, 1510-1800. Milwaukee: University of Wisconsin, 1965.

CARRARA, Angelo Alves. Receitas e despesas da Real Fazenda no Brasil. Juiz de Fora: Universidade Federal de Juiz de Fora, 2010.

COSTA, Leonor Freire. O transporte no Atlântico e a Companhia Geral de Comércio do Brasil (1580-1663). Lisboa: CNCDP, 2002.

DIAS, Marcelo Henrique. "Economia, sociedade e paisagens da capitania e comerca de Ilhéus no período colonial”, Tese de doutorado, UFF, Niterói, 2007.

FIGUEIREDO, Luciano Raposo de Almeida. "Revoltas, fiscalidade e identidade colonial na América portuguesa: Rio de Janeiro, Bahia e Minas Gerais, 1640-1761”. Tese de Doutorado, São Paulo, USP, 1996.

Rebeliões no Brasil Colônia. Rio de Janeiro: Jorge Zahar, 2005.

GALLO, Alberto. "Racionalidade fiscal e ordem estamental: a cobrança dos dízimos brasileiros nos séculos XVII e XVIII”. Colóquio Internacional: Economia e colonização na dimensão do Império português. São Paulo: Cátedra Jaime Cortesão, 2008.

HANSEN, João Adolfo. A sátira e o engenho: Gregório de Matos e a Bahia do século XVII. 2 ed. Campinas: Unicamp, 2004.

JOYCE JR., Joseph Newcombe (Ph.D.). Spanish influence on Portuguese administration. A study of the Conselho da Fazenda and Hapsburg Brazil, California: University of Southern California, 1974.

LENK, Wolfgang. Guerra e pacto colonial: exército, fiscalidade e administração colonial da Bahia (1624-1654) (Tese de doutoramento), Campinas, UNICAMP, 2009.

MENDONÇA, Marcos Carneiro de. Raízes da formação administrativa do Brasil. Rio de Janeiro: IHGB, 1972.

73 AHU/BA/SÉRIE LUÍSA DA FONSECA/CARTA de Francisco Barreto a S.M., 4 de junho de 1661 [cx. 16, doc. 1811] - grifo no original. Note-se que o governador definiu riqueza como a posse de cabedal invertido na produção da colônia (escravos, especialmente), de uma forma mais ampla de como era definida pela Câmara e pelo povo. 
OLIVAL, Fernanda. As ordens militares e o Estado moderno: honra, mercê e venalidade em Portugal (1641-1789). [s.1.]: Estar, 2001.

PUNTONI, Pedro. "O conchavo da farinha: espacialização do sistema econômico e o Governo Geral na Bahia do século XVII”. Simpósio de Pós-Graduação em História Econômica, São Paulo, 2008 (versão preliminar).

RICUPERO, Rodrigo M. "Honras e mercês: poder e patrimônio nos primódios do Brasil”. Doutorado em História Econômica. São Paulo, FFLCH/Dep. de História, USP, 2005.

SOUZA, Laura de Mello e. O sol e a sombra: politica e administração na América portuguesa do século XVIII. São Paulo: Companhia Das Letras, 2006.

VASCONCELOS, Antônio Augusto Teixeira de. O conde de Castelo Melhor,João Rodrigues de Vasconcellos. Lisboa: Universal, 1874. 